Review

\title{
Shedding Light on Manic Syndromes and Dementia
}

Gabriele Cipriani ${ }^{1, *}$, Sabrina Danti ${ }^{2}$, Cecilia Carlesi ${ }^{3}$, Claudio Lucetti ${ }^{4}$, Angelo Nuti ${ }^{5}$, Mario Di Fiorino ${ }^{6}$

1. Gabriele Cipriani Neurology Unit, Versilia Hospital, Lido di Camaiore, Italy, Psychiatry Unit, Versilia Hospital, Lido di Camaiore, Italy; E-Mail: cprgrl@gmail.com

2. Sabrina Danti Clinical and Health Psychology Unit, Hospital of Pontedera, Pontedera, Italy; EMail: danti.sabrina@gmail.com

3. Cecilia Carlesi Neurology Unit, Versilia Hospital, Lido di Camaiore, Italy; E-Mail: cecilia.carlesi@gmail.com

4. Claudio Lucetti Neurology Unit, Versilia Hospital, Lido di Camaiore, Italy; E-Mail: claudio.lucetti@libero.it

5. Angelo Nuti Neurology Unit, Versilia Hospital, Lido di Camaiore, Italy; E-Mail: angelonuti1@virgilio.it

6. Mario Di Fiorino Psychiatry Unit, Versilia Hospital, Lido di Camaiore, Italy; E-Mail: difiorinomario@yahoo.it

* Correspondence: Gabriele Cipriani; E-Mail: cprgrl@gmail.com

Academic Editor: Ladislav Volicer

Special Issue: Behavioral Symptoms of Dementia

OBM Geriatrics

2019, volume 3 , issue 3

doi:10.21926/obm.geriatr.1903070
Received: March 27, 2019

Accepted: August 08, 2019

Published: August 16, 2019

\begin{abstract}
Background: Mania in older adults is associated with a high rate of medical and neurological disease.

Objective: The goal of this review is to describe the phenomenon of manic episodes in patients suffering from dementia.

Methods: Medline and Google Scholar searches were conducted for relevant articles, chapters, and books published before 2019. Search terms used included dementia, late-
\end{abstract}


onset, mania, and elderly. Publications found through this indexed search were reviewed for further relevant references.

Results and Conclusions: Manic states in older adults often present with confusion, disorientation, distractibility, and irritability rather than elevated, positive mood. The literature on mania and hypomania in dementia is limited. It consists mostly of case reports and small samples of patients.

\section{Keywords}

Dementia; late-onset; mania; elderly

\section{Introduction}

Dementia includes impairments in cognitive skills associated with gradual loss of functional status and ability to perform everyday activities. Decline in memory is considered a hallmark symptom of dementia, but non-cognitive symptoms such as changes in personality [1], delusions $[2,3]$ (sometimes in bizarre forms [4, 5]), misidentification syndromes [6], mood changes [7], sexual disinhibition [8], wandering [9], aggressive behavior [10], and other neuropsychiatric symptoms $[11,12]$ are also prevalent, especially during later stages. Alois Alzheimer, describing the disease that bears his name, reports symptoms such as delusions, hallucinations, and verbal outbursts [13]. Late-onset mania has been considered rare, but sometimes, it is described in patients suffering from dementia.

\section{Manic Clinical Features}

Aspects of mania represent exaggerations of normal behaviors. Clinical pictures of mania and melancholia do not differ substantially from the description proposed by Kraepelin's psychiatric nosology [14] but a debate has opened on the nosographic borders of the manic-depressive illness.

Manic symptoms cover a spectrum of severity from cyclothymia to severe delirious mania [15]. Klerman described a continuum from normal happiness or joy through mild changes that remain within the normal range, cyclothymic and hypomanic personalities, psychotic mania, and delirious mania. He suggested naming this manic spectrum with the term "elation" [15]. The manic mood is not always decidedly oriented towards gaiety. Even the more good-natured manic patient does not tolerate being contradicted and easily gets angry. Therefore, the dysphoric mood becomes evident (dysphoria: from the Greek dysphoros = hard to bear). The exaltation of affectivity can be transformed from an unbridled joy in a turbulent moodiness and in a dangerous litigiousness [16]. The patient is restless and impulsive; he always needs to do something, and the ideas are immediately transformed into actions, often indelicate and inopportune. The patient speaks without stopping and imagination is exalted. The manic syndrome is phenomenologically "positive," including elated mood, expansiveness, dysregulated sleep, increased energy and activity, accelerated ideation, and hypertrophic self-esteem [17]. However, the psychopathological structure of mania also includes negative components such as the weakening of thinking skills and the reduction of conative attention with difficulty concentrating on a topic and following a speech. 
The fundamental and prevailing tone of the manic state is represented by affective exaltation; when emotional expression is fleeting, periods of despair, apprehension, and tearfulness intermingle with euphoria [18]. Unlike what is believed, the manic patient is not usually sympathetically euphoric; self-assertion occurs through contempt for others, which can be manifested by verbal or physical aggression. Joking, facetious, yielding attitudes often give way suddenly to anger and bad moods, configuring a mixed type of manic symptomatology with the co-presence of opposite polarity symptoms, due to their rapid alternation [19]. Moderateness, poise, and composure disappear and loss of normal social inhibitions and behaviors that contrast with education and personality characteristics emerge. The behavioral abnormalities encompassed by disinhibition (e.g. unrestrained buying sprees, sexual disinhibition) overlap with the psychopathology of some form of secondary mania. Regarding temporality, it is based on the "here and now." The patient lacksan understanding of the concept of unfolding over time: he lives only in the "now" and in the "now" all his/her contacts with the environment are limited [16]. Among the clinical features of mania, delusions and hallucinations are described in the current edition of the Diagnostic and Statistical Manual (DSM-5) of the American Psychiatric Association [20]. Delusions are frequent psychopathological characteristics during manic episodes. Grandiose delusions are present in up to $60 \%$ of cases, while between $18 \%$ and $65 \%$ of patients experience persecutory delusions; auditory hallucinations are found from $7 \%$ to $48 \%$ of cases [21]. A serious clinical condition is the so called "Bell's mania" also known under the name of delirious mania. Quite succinctly, it consists of the overlapping of manic symptoms with those of the clinical picture of the delirium representing a potentially life-threatening disorder. This condition has no formal diagnostic classification. When, in the 19th century, Luther Bell described this clinical picture, he underlined its sudden onset, severe insomnia, loss of appetite, exceedingly great over-activity, the presence of hallucinations and extremely bizarre delusions, and the rise of confusion [22]. Some authors have described a close relationship of delirious mania with catatonia [23]. According to Bipeta et al. [24], Bell's mania is often ignored and misdiagnosed in clinical practice. It poses a diagnostic dilemma for clinicians and constitutes a therapeutic challenge.

\section{Primary and Secondary Mania}

In 1978, Krauthammer and Klerman proposed the concept of secondary mania as a syndrome with multiple causes [25]. "Primary mania" (or "idiopathic" or "essential" mania) is habitually considered as a phase of manic-depressive disease, whereas "secondary mania" (or "organic mania") consists of an expansive episode that complicates various types of neurological, endocrine, or toxic-metabolic pathologies in the absence of previous history of affective disturbance [20]. For example, manic features may derive from the intake of some substances, such as amphetamine, cocaine, and volatile substances (i.e. paints and gasoline). We must also consider the cases in which medical illnesses affect patients with bipolar disorder (BD) without any correlation between the two illnesses [26]. On a diagnostic level, it is very important to distinguish a primary mania from a secondary mania given the important prognostic and therapeutic implications (removal, where possible, of the etiopathogenetic factor) [4]. The clinical and anamnestic aspects suggestive of secondary mania are: an identifiable medical condition that has temporally preceded a mood syndrome, mania (usually, the manic/hypomanic picture due to a medical condition may appear within weeks or a few months), negative personal premorbid history, absence of family history for 
mood disorders, and senile age onset [25]. A nosographic problem that has been asked is whether it is right to exclude patients with a history of affective disorder from the category of organic mania [25]. In fact, some argue that organic pathology only promotes the emergence of primary affective symptoms. It will be impossible to dispel the doubt until a biological marker is developed to identify idiopathic BD [27].

Although secondary mania is a condition that may occur at any point across the lifespan, older people, being more fragile, showing a high prevalence of comorbid medical conditions, and presenting a high probability of taking multiple medications, are at risk of presenting a secondary mania [28]. Authors [25] noted that relatively late age at onset (over 40 years) was a characteristic of manic states associated with medical or neurological conditions or drugs. Manic states may develop after a heterogeneous group of organic disorders [29] including, but not limited to, stroke [30], HIV infection [31], partial seizures (both simple partial and complex partial seizures) [32], and intracranial space-occupying lesions [33]. Corticosteroids were most often involved in the cases of organic mania due to medications [34]. Other medications and substances that induce mania in patients without BD are levodopa, atypical antipsychotic drugs, monoamine oxidase inhibitors (MAOIs), alcohol, and cocaine [35].

\section{Neuroanatomic Basis of Manic Symptoms}

Emotional regulation refers to the process that influences which emotions we have, when we have them, and how we experience or express them [36]. How brain damage gives rise to manic symptoms is not perfectly known. Many different abnormalities of brain function and structure have been proposed to explain the behavioral signs of secondary mania. Scientific literature suggests results that are not always satisfactory and sometimes conflict with each other, but rightsided brain lesions seem to predominate among patients with lesional mania [37, 38]. Several circuits and brain areas may be affected especially in the right basotemporal regions of the limbic system and in the basal ganglia including the head of the right caudate nucleus [30, 39-41]. Many authors sustained that a right orbitofrontal damage is essential for the appearance of a secondary mania [39, 42, 43]. It has been assumed that the interruption of fronto-temporal circuits contributes to the onset of manic symptoms. The frontal lobes probably are involved in elaborating an inhibitory influence upon the limbic systems and an interruption in the frontotemporal pathways could lead to release of limbic functions from inhibition and potentially a manic syndrome [44]. In some studies, manic symptoms significantly correlated with cerebellarpontine lesions because these areas are connected with frontal and posterior parietalsubcortical-thalamic circuitry via inputs to the thalamus [45-47]. Secondary manic syndrome may occur with solitary lesions affecting the temporal lobe [37, 41]. The left frontal lobe is a hub for positive emotion (i.e. happiness) generation [48]. Emotional dysregulation with persistent elevations in positive emotion may generate debilitating clinical symptomatology such as mania, risk-taking, and disinhibition.

\section{Manic Syndrome in the Elderly}

According to statistics, mania affects about $1 \%$ of the population over the age of 18 [49]. No statistically significant differences were found in the distribution of the disorder between the two sexes. The most frequent onset age of idiopathic manic-depressive illness is around 30 years, with 
minor episodes in the early 20s [37]. There is strong evidence of a genetic component of the disorder [37]. It can present for the first time in old age, with a third peak (especially in males) in the eighth and ninth decades [50]. However, the incidence of new onset mania is generally believed to decline over the course of a lifespan [51]. The incidence of mania at age $>75$ years has been reported to be approximately only 2 per 100,000 persons [52]. Generally, elderly patients have been found to have suffered more episodes of depression before a first manic episode; some patients have developed a first manic episode after age 60 [29]. Other older individuals developed new-onset mania without any past psychiatric illness [29]. There are controversies concerning the clinical expression of mania in old age. As reported by Broadhead and Jacoby [53], it appears that the clinical profile of first-episode mania in the elderly is not fundamentally different from the presentation in young patients with mania. In reverse, according to George [54], the clinical picture is characterized not so much by inhibition as by the presence of anxious restlessness, dysphoria or irritability, and negativity. Hostility is prominent. There are confusional features and paranoid ideation (persecutory delusions are more common in the elderly). Slater and Roth [55] commented that in elderly manics, speech and thought lack the typical "sparkle and versatility" and are commonly "threadbare and repetitious," overall severity may be "relatively mild;" on the other hand, "hostility and resentment" are often marked. Furthermore, mania in older adults can have more of a major negative impact than in younger adults; older manic patients compared with younger adults presented higher rates and longer duration of hospitalization and showed a slower rate of improvement $[28,56]$. Older patients may develop cognitive problems during an acute manic episode that appear clear after the episode resolves (i.e. manic pseudodementia); similarly, a demented patient with mania may also be misdiagnosed as an agitated dementia patient without an affective disorder [57]. Of interest is a study finding that $20 \%$ of first-episode manic patients over 60 years of age had a close temporal association between the onset of mania and evidence of cerebral organic disorder [53]. In one retrospective study of 50 patients with mania who were older than 65 years, it was the first manic episode for $28 \%$ of the patients and $71 \%$ had a comorbid neurological disorder [58].

\section{Mania and Dementia}

A serious and common complication of dementia is the occurrence of mental and behavioral disturbances. Late-onset mental illness is often symptomatic of medical or neurological conditions. There is an intricate and composite relationship between mood disorders and cognitive impairment. They can precede cognitive dysfunction being a "risk factor" for dementia; on other occasions, cognitive changes have been interpreted as a residual symptom of affective disorders $[59,60]$. Nillson et al. [61] found an increased probability of developing major depressive disorder or developing a manic episode in patients with dementia compared with patients with other chronic and disabling medical illnesses. Manic states are considered unusual in dementia, and elderly demented patients with manic-like symptoms are sometimes misdiagnosed as having delirium, especially if the symptoms are dominated by disorganised thinking, as in severe mania [61]. Authors suggested that dementia releases latent bipolarity in individuals with certain predispositions, such as affective temperaments (the term "temperament" refers to the emotional domain of personality) [62]. Although an epidemiologic study suggested that the increased incidence in first hospitalizations for mania in late life was due to an association with dementia 
[63], this has not been supported by subsequent studies [53, 64-66]. There are differences in the presentations and premorbid histories of dementia and mania. According to Brooks and Hoblyn [28], dementia would likely be preceded by changes in cognitive abilities in the absence of affective symptoms; the cognitive changes of dementia usually occur over years, in contrast to those of primary mania, which are abrupt and accompanied by affective symptoms. Appleby and Rosenberg [67] described an elderly patient who was diagnosed with dementia following a solitary episode of mania. The literature has recently described several commonalities in the pathophysiological processes of BD and dementia. In addition to bipolar I and bipolar II, researchers proposed adding bipolar variants III, IV and V. Recently, others suggested creating a new category at the intersection of bipolarity and dementia; a variant of BD, defined as type VI [62] which is characterized by mixed-labile mood symptoms and cognitive dysfunction associated with hyperthymic/cyclothymic/irritable temperament, family history of $B D$, refractoriness to antidepressants and acetylcholinesterase inhibitors but favourable response to mood stabilizers and/or atypical antipsychotics [68]. We try to describe the phenomenon of mania in some subtypes of dementia.

\section{Alzheimer's Disease (AD)}

$A D$ is the most common form of dementia characterized by an insidious onset and a chronic and slowly increasing progression that leads to a serious interaction and impairment in the activities of daily life. If the first symptoms are in the cognitive sphere, with the progression of the disease the neuropsychiatric manifestations become more significant. Depressive symptoms occur commonly in patients with $A D$ [7]. By contrast, mania is rare. Aspects of irritability and aggression associated with cognitive impairment and functional decline may be misdiagnosed for late onset BD (LOBD) [69]. There is also important clinical evidence linking $A D$ and $B D$ as well in the clinical course (just think of the mixed rapid cycling episodes of $B D$, which often have the clinical presentation of dementia) and in residual symptoms being known for stable and lasting cognitive dysfunctions in all phases of BD. There is a discrepancy between an expert observer's assessment and patients' awareness of the presence of manic symptoms. Among the first, 3.5\% experienced manic symptomatology, while among the latter only one patient among 110 recognized the presence of the disorder [70]. According to Lyketsoset et al. [49], the prevalence of mania among people living with $A D$ is $2.2 \%$. However, a study carried out at Memory Clinics between people with moderate to severe AD has shown that euphoria manifestations occur in $15 \%$ of patients; these attitudes are however considered mildly distressing by the caregivers [71]. There are very limited reports on mania induced by cholinesterase inhibitors (CHEIs).

Scientific literature [72] describes the case of a 76-year-old Taiwanese man suffering from AD with no past psychiatric history. He was scored on the Mini Mental State Examination (MMSE). Treatment with rivastigmine induced the first episode of manic-like symptoms. The patient developed irritability, psychomotor activation, aggressive behaviours coupled with an increase in energy and decreased need for sleep, pressured speech, inappropriate repetition of the same questions and continuous phoning. Other authors [73] described a case of a manic episode with psychotic features associated with the up-titration of donepezil in a patient with $A D$ and a distant history of major depression but without pre-existing BD. Further two cases of mania after administration of a CHEI (galantamine) were reported [74]. 


\section{Frontotemporal Dementia (FTD)}

In 1904, Professor Arnold Pick presented now historical case reports of non-Alzheimers dementias laying the foundations for understanding a spectrum of diseases defined as FTD characterized by degeneration of circumscribed areas of atrophy of the brain (the frontal and temporal lobes) [75]. It is both clinically and pathologically heterogeneous, bringing a gradual, progressive decline in behaviour, language, or movement, with memory usually relatively preserved. There are three types of FTD and they lead to different changes: 1) behavioural variant FTD (bvFTD), the most common form of FTD, responsible for about half of all cases of this disease, with frontal lobe-predominant atrophy, typically recognized for decline in socially appropriate functions and changes in behavior; 2) semantic dementia (SD), presenting with amodal and profound loss of semantic knowledge (combination of visual associative agnosia, anomia, surface dyslexia or dysgraphia, and disrupted comprehension of word meaning) and behavioral abnormalities, attributable to the degeneration of the anterior temporal lobes; 3 ) progressive nonfluent aphasia characterized by agrammatism, laborious speech, alexia, and agraphia, frequently accompanied by apraxia of speech (language comprehension is relatively preserved). Despite the progress in clinical diagnosis, the definitive diagnosis and distinction of individual FTD is currently only possible with neuropathological examination of the brain. The most frequent clinical presentations of bvFTD are apathy [76], early change in personality and social behavior [77] including loss of manners, presence of dietary changes [78], and ritualistic compulsive behaviours [79]. Wandering and pacing are common, often involving a fixed route [9]. Sometimes, the behavioral anomalies described during bvFTD, such as restlessness, a lack of interpersonal etiquette, exhibitionism, loss of decorum and tactlessness, and uncontrolled sexuality depict a cluster of symptoms that closely resembles the narration of a manic patient. These changes can be dramatic and may be misdiagnosed as a psychiatric disorder. Behavioural symptoms such as "moria" (a happy-go-lucky carelessness and silly facetious humour), inappropriate jocularity and childish humour, frivolous behavior, increase in self-confidence, and irritability may cause misdiagnosis as hypomania or mania as well $[80,81]$. Some patients are disinhibited, overactive and restless, and may clown, sing, and dance [82]. They may show press of speech, tangentiality where the patient will reply to a question in an oblique or irrelevant manner, derailment (a grammatically and syntactically correct speech suddenly interrupted by seemingly unrelated ideas), focusing on specific words and even clanging and punning [83]. Researchers have shown a relationship between "acquired extroversion" and manic-like euphoria with a right temporal predominant bvFTD $[83,84]$ (extroversion refers to dispositions toward energy, activity, positive affect, and sociability) [1]. Hypomania-like behaviors are predominant when temporal areas are impaired, while apathy, and decrease in social activities are predominant when frontal areas are affected [85]. In fact, patients with prevalent involvement in temporal areas are particularly at risk for developing deficits in emotional processing secondary to atrophy in the amygdala, anterior temporal cortex (ATC), and orbital frontal cortex (OFC), structures that are components of the brain's emotional processing systems. Mendez [86] illustrated the relationship of manic behavior and bvFTD in a subject with thought associations that jump from topic to topic, distractibility and attentional problems, and psychomotor disturbance. Nuclear magnetic resonance revealed predominant right fronto-temporal involvement, with relative sparing of the left frontal lobe. The patient had a novel mutation in the progranulin (GRN) gene on chromosome 17 . According to Dols 
[87] and colleagues, symptoms fitting the criteria for possible bvFTD may be present in the endstage of BD. Meisler and colleagues [88] reported C9ORF72 expansion (it is involved in the processes of intracellular vesicle trafficking) in a family with BD and FTD, highlighting a possible etiological relationship between the C9ORF72 expansion and disease progression from BD to FTD.

\section{Vascular Dementia (VaD)}

VaDs represent, on the etio-pathogenetic level, a heterogeneous group of pathologies that recognize as a common pathophysiological moment, a cerebral vascular damage (ischemic, hypoxic, haemorrhagic) that manifests itself clinically with symptoms and signs of a dementia. Late onset mood disorders, including mania, have generally been reported to be associated with vascular risk factors [89]. However, in contrast to the burgeoning literature relating to vascular depression, little has been written on what might be considered as the opposite side of the same coin. The concept of vascular mania as a subtype of mania was proposed by Steffans and Krishnan to sub-classify patients presenting with manic symptoms and concurrent significant evidence of cerebrovascular disease [90]. Although there is no universally accepted definition or criteria for diagnosing vascular mania, many researchers believe that cerebrovascular risk factors such as lacunar infarcts, recurrent transitory ischemic attacks, history of hypertension, and hypercholesterolemia contribute to the rise of a manic syndrome [91]. The idea is similar to that of "vascular depression" proposed by Alexopoulous et al. [92]. The frequency of mania in patients with $\mathrm{VaD}$ is generally considered to be rare. Post-stroke manic syndrome recurs in about $1 \%$ of cases [42]. Santos et al. [93] performed a systematic review of all cases of mania and stroke. They confirmed the rarity of post-stroke-mania because in about 50 years they found only 74 reported cases of adult stroke patients with mania symptoms. The localization of lesions was reported on the frontal lobe (including the orbitofrontal cortex), temporal lobe, basal ganglia (head of caudate nucleus), and thalamus [94-96]. Regions connected to the limbic cortex have been implicated in late-onset mania. It has been suggested that dysfunction of the fronto-limbic circuits could negatively influence mood modulation resulting in the expression of bipolarity through manic symptoms. There is a significant relationship between post-stroke mania and right hemispheric lesions, but there are also reports of mania following left sided lesions [97]. A mechanism implying the activation or release of left hemisphere influence after a right hemisphere contralesion has been proposed. Takahashi et al. [98] valuated the presence of white matter hyperintensities on T2-weighted magnetic resonance images (WMHs), reporting a higher incidence of these neuropathological changes in frontal areas and the left parieto-occipital area of patients with laterather than early-onset affective illness. Of relevance is the finding of a high incidence of agerelated silent cerebral infarctions (SCls) (20\%) in late-onset mania [99]. Fujikawa et al. [100] suggested that $\mathrm{SCl}$ have been detected in approximately half of people who developed mania after 50 years. The temporal relationship between stroke and mania ranges from immediately post-stroke to up to two years thereafter [101]. However, the majority of mania cases seem to appear within the first month following a stroke [102]. Authors [103] described the case of a 64year-old right-handed man suffering from bipolar II disorder (BPII) who presented with mania after the occurrence of $\mathrm{VaD}$ with left fronto-temporal lobe infarction. His manic state lasted for about 4 months and after mania, he returned to marked symptoms of dementia without affective symptoms. They hypothesized that dementia may amplify mood fluctuation (i.e. worsening 
hypomania to mania). A form of microvascular disease, subcortical arteriosclerotic encephalopathy, or Binswanger's disease was the probable source of new onset mania in one 65year-old man [104]. Bangash and colleagues [105] reported manic symptoms in a 62-year-old woman suffering from cerebral autosomal dominant arteriopathy with subcortical infarcts and leukoencephalopathy (CADASIL), a genetic cerebral angiopathy due to a small mutation in the Notch3 gene situated on chromosome 19 and characterized by mid-adult onset of recurrent subcortical ischemic episodes and slow cognitive decline progressing to dementia.

\section{Dementia with Lewy Bodies (DLB)}

DLB is a clinical entity characterized by a progressive symptomatology, mainly cognitive and psychiatric, correlated from a neuropathological point of view by the presence of neuronal inclusions (Lewy bodies). The cardinal clinical triad that characterizes the DLB is represented by marked fluctuating cognitive impairment, persistent visual hallucinations, and extrapyramidal signs (EPS). Other typical clinical manifestations are marked sensitivity to neuroleptics, the presence of REM sleep disorders, and autonomic dysfunction. The case of an 82-year-old woman with DLB admitted to the hospital due to manic symptoms was described [106]. The patient, referred to a Department of Old Age Psychiatry, had elevated mood with persistent joyfulness, pressure of speech, and flight of ideas. She was trying to attract a male's attention and she meddled in speeches with inappropriate humorous jokes.

Informant history from a close friend revealed that she had a very clear history of fluctuation in her cognitive state. Auditory hallucinations were present. Physical examination showed mild bradykinesis and a kyphotic posture. Prado et al. [107] presented the case of a 70-year-old man with a diagnosis of probable DLB treated with modafinil (2-[(Diphenylmethyl) sulfinyl] acetamide). The drug is currently authorized for the following indications: excessive sleepiness caused by sleep apnea, narcolepsy, or shift work sleep disorder. Modafinil has also been used as option for excessive daytime somnolence in DLB. The exact dose and duration of the patient's treatment is unknown, but the patient's wife indicated that he soon began having symptoms of agitated mania and sleeplessness, was abusive and loud, and destroyed things in his house. His condition improved markedly with discontinuation of modafinil. A review of the literature failed to reveal other reported cases of mania occurring in DLD.

\section{Parkinson's Disease Dementia (PDD)}

In 1817 James Parkinson identified the term "Shaking palsy" as one of the most common age related neurodegenerative diseases. He presented it as a movement disorder and described a relationship between mood disorders and the illness [108]. Parkinson's disease (PD) is a progressive neurological disorder that affects, predominately, dopaminergic neurons in a specific area of the brain, the pars compacta of the substantia nigra. Patients present with motor symptoms such as bradykinesia, rigidity, and resting tremors. However, non-motor symptoms such as constipation, orthostatic hypotension, diaphoresis, loss of sense of smell, and cognitive impairment may be prominent. Affective and behavioral disturbances may precede or follow the diagnosis [109]. This comorbidity probably reflects the changes that occur in the complex functional circuit that includes the basal ganglia, thalamus, limbic structures, and prefrontal cortex. In recent years it has been understood that the dementia associated with PD (PDD) is more 
widespread than previously thought. It is one of the most common non-motor symptoms in patients with PD, with a prevalence that reaches almost $100 \%$ in the long term with an average latency of about 10 years from diagnosis.

PDD has been increasingly better recognized, probably because patients with PD survive for longer than before thanks to modern treatment. Cognitive symptoms include deficits in executive, attentional, and visual-spatial functions and moderately impaired memory associated with apathy, anxiety, hallucinations, and delusions [76]. The main distinguishing criterion between DLB and PDD is of a temporal nature: the diagnosis of DLB should be made when cognitive decline occurs before, simultaneously, or within one year of the onset of parkinsonism ("one year-rule") [110]. Both clinical phenotypes can be considered jointly within categories such as $\alpha$-synucleinopathies since both nosological entities share neuropathological features, i.e. the abnormal accumulation in neuronal and glial cells of insoluble aggregates, defined Lewy bodies containing the $\alpha$ synaptic protein sinuclein. Mindham [111] found no evidence of mania in a retrospective study of 89 patients, but, subsequently, manic episodes were described [112]. It has long been thought that dopaminergic drugs can precipitate mania. The psychiatric adverse effects of levodopa were reviewed by Goodwin [113]. Of 908 patients treated with levodopa, 33 (3.6\%) developed overactivity, restlessness, or agitation and 14 patients (1.5\%) were regarded as experiencing frank hypomania. There are also case reports of mania during with use of other antiparkinsonian medication: selegiline [114], bromocriptine [115], pramipexole [116], ropinirole [116], and apomorphine [117]. These symptoms often resolved after discontinuation or reduction of the offending agent $[118,119]$. Significant manic features are described in the course of PD treatment as part of the dopamine dysregulation syndrome (DDS) $[120,121]$. The most common symptom of this neuropsychiatric behavioral syndrome is compulsive use and self-escalation of dopaminergic medications. Also, impulse control problems like punding, overeating, or other addiction-like behaviours, and mood and behavioral changes may occur, as a result of dopamine dysregulation. In DDS, patients often develop mood fluctuation such as manic-like behaviors including aggression, pathological gambling, hypersexuality, and/or compulsive gambling or shopping that may switch into a depressive episode with social withdrawal and psychomotor slowing becoming a cyclical-like mood disturbance [122].

\section{Huntington's Disease (HD)}

$\mathrm{HD}$ is a rare, fatal, neurodegenerative disease inherited in an autosomal dominant fashion, caused by an expansion of the cytosine-adenine-guanine (CAG) repeat sequence in the IT15 gene on the short arm of chromosome 4 (4p16.3), which encodes an abnormal protein (called huntingtin). Length of CAG repeats is correlated with the age of onset and severity of the symptoms; patients with fewer CAG repeats tend to have a later disease onset and milder symptoms compared to those with longer repeats. The disease is characterised by movement disorders (chorea, dystonia, bradykinesia, oculomotor dysfunction), severe behavioral alterations, and progressive cognitive deterioration. The variability of symptoms experienced by people with $\mathrm{HD}$ has been found to be correlated with the degeneration of different regions of the brain. Neuropsychiatric symptoms develop gradually as the disease progresses, but sometimes they may be the symptoms of onset of HD and manifest before the motor symptoms. Depression is the most frequently observed psychiatric disorder in HD. Other psychiatric disorders that occur in 
Huntington's patients include obsessive-compulsive disorder, a condition with recurrent, intrusive thoughts and repetitive behaviours. Mania-like symptoms are rarer. It was found that they are present in $4.8 \%$ of cases [123]. They manifest themselves with irritable behavior or elevated mood, feelings of high self-esteem, over-activity, reduced sleep, hypersexuality, and grandiose or paranoid delusions [124]. Mania and bipolar syndromes have a lifetime prevalence of $2 \%$ to $12 \%$ in $H D$, higher than would be predicted by chance $[123,125,126]$. The nosographic classification is not simple, requiring a lot of attention. In fact, symptoms that recall the manic state such as disinhibition are common during the course of the disease.

\section{Treatment Strategies}

There are no clear guidelines available regarding pharmacologic therapies of mania in the elderly and medical care of older adults generally follows similar guidelines as for younger adults. Treatment should be initiated to attenuate the symptoms which impair the patient's quality of life or which jeopardize them or those around them. In secondary mania, medication of the organic cause can contribute to successful management of manic episodes. General principles of prescription in the elderly should be considered given pharmacokinetics, side effects of medication, concomitant medication use, and comorbidity. It will be necessary to prefer drugs with a greater therapeutic margin and with less possibility of interactions with medications usually taken in the geriatric age. If a patient was being treated with an antidepressant before the manic episode, this should generally be stopped. In general terms, the most common psychopharmacologic regimen includes lithium salts, anticonvulsants (such as sodium valproate, gabapentin, lamotrigin, topiramate, carbamazepine, or oxcarbazepine), and atypical antipsychotics (olanzapine, risperidone, quetiapine, clozapine, and ziprasidone). Special care should be taken when introducing lithium (it is problematic in patients with renal disease and other medically ill patients). It should be considered that liposoluble substances such as benzodiazepines and antipsychotics accumulate in body fat and persist in their effects longer than expected.

\section{Conclusions}

In clinical practice, we encounter situations that require precise differential diagnosis and special treatment. Mania can be primary, resulting from BD, or secondary, related to underlying medical or neurological conditions, substance use, or psychotropic drugs. Manic states occurring for the first time in late life run an atypical course. It is an uncommon, heterogeneous condition with an often atypical presentation. The exact mechanism by which brain insults lead to mania is unclear, although there is evidence of associations between right-sided lesions and mania. Despite its clinical importance, there are few specific studies about mania or hypomania in late life. A first episode in an elderly patient can be quite problematic, showing irritability, confusion, disorientation, and distractibility, rather than elevated, positive mood. Although infrequent, manic episodes have been reported in patients with dementia, and physicians should be aware of the phenomenon and not overlook it. Because it is so highly associated with behavioral agitation, mania has a significant impact on patient management. We should not forget the importance of a good clinical history and anamnesis to reach a correct diagnosis as well as an organized and carefully planned treatment approach for each patient. 


\section{Author Contributions}

Gabriele Cipriani conceived and planned the article; Sabrina Danti, Cecilia Carlesi, Claudio Lucetti, Angelo Nuti, Mario Di Fiorino contributed to the design and implementation of the review, and to the writing of the manuscript.

\section{Competing Interests}

The authors have declared that no competing interests exist.

\section{References}

1. Cipriani G, Borin G, Del Debbio A, Di Fiorino M. Personality and dementia. J Nerv Ment Dis. 2013; 3: 210-214.

2. Cipriani G, Danti S, Vedovello M, Nuti A, Lucetti C. Understanding delusion in dementia: A review. Geriatr Gerontol Int 2014; 14: 32-39.

3. Cipriani G, Logi C, Di Fiorino A. A romantic delusion: De Clerambault's syndrome in dementia. Geriatr Gerontol Int. 2012; 12: 383-387.

4. Cipriani G, Lucetti C, Danti S, Ulivi M, Nuti A. Uncommon and/or bizarre features of dementia. Acta Neurol Belg. 2015; 115: 19-25.

5. Cipriani G, Nuti A, Danti S, Picchi L, Di Fiorino M. 'I am dead': Cotard syndrome and dementia. Int J Psychiatry Clin Pract. 2019; 8: 1-8.

6. Cipriani G, Vedovello M, Ulivi M, Lucetti C, Di Fiorino A, Nuti A. Delusional misidentification syndromes and dementia: A border zone between neurology and psychiatry. Am J Alzheimers Dis Other Demen. 2013; 28: 671-678.

7. Cipriani G, Lucetti C, Carlesi C, Danti S, Nuti A. Depression and dementia. A review. G. Eur Geriatr Med. 2015: 5; 479-486.

8. Cipriani G, Ulivi M, Danti S, Lucetti C, Nuti A. Sexual disinhibition and dementia. Psychogeriatrics. 2016; 16: 145-153.

9. Cipriani G, Lucetti C, Nuti A, Danti S. Wandering and dementia. Psychogeriatrics. 2014; 14 : 135-142.

10. Cipriani G, Vedovello M, Nuti A, Di Fiorino M. Aggressive behavior in patients with dementia: Correlates and management. Geriatr Gerontol Int. 2011; 11: 408-413.

11. Cipriani G, Lucetti C, Danti S, Carlesi C, Nuti A. Violent and criminal manifestations in dementia patients. Geriatr Gerontol Int. 2016; 16: 541-549.

12. Cipriani G, Vedovello M, Lucetti C, Di Fiorino A, Nuti A. Dementia and suicidal behavior. Aggress Viol Beh. 2013; 18: 656-659.

13. Cipriani G, Dolciotti C, Picchi L, Bonuccelli U. Alzheimer and his disease: A brief history. Neurol Sci. 2011; 32: 275-279.

14. Kraepelin E. Manic-Depressive Insanity and Paranoia. Edinburgh: E\&S Livingstone Ltd; 1921.

15. Klerman GL. The spectrum of mania. Compr Psychiat. 1981; 22: 11-20.

16. Fuchs T. Psychopathology of depression and mania: symptoms, phenomena and syndromes. J Psychopathol. 2014; 20: 404-413.

17. Young RC, Klerman GL. Mania in late life: Focus on age at onset. Am J Psychiatry. 1992; 149: 867-876. 
18. Taylor MA, Vaidya NA. Descriptive psychopathology: The Signs and Symptoms of Behavioral Disorders. Cambrige University Press; 2008. p 215.

19. Marneros A, Deister A, Rohde A, Sakamoto K. Psychopathology of K. Schneider's mania. J Psychiatry Neurol. 1988; 42: 11-15.

20. American Psychiatric Association. DSM-5 diagnostic and statistical manual for mental disorders. 5th ed. Washington, DC: American Psychiatric Association; 2013.

21. Dunayevich E, Keck PE Jr. Prevalence and description of psychotic features in bipolar mania. Curr Psychiatry Rep. 2000; 2: 286-290.

22. Bell LV. On a form of disease resembling some advanced stages of mania and fever. Am J Insanity. 1849; 6: 97-127.

23. Taylor MA, Fink M. Catatonia in psychiatric classification: A home of its own. Am J Psychiatry. 2003, 160: 1233-1241.

24. Bipeta R, Khan MA. Delirious Mania: Can we get away with this concept? A case report and review of the literature. Case Rep Psychiatry. 2012; 2012: 720354.

25. Krauthammer C, Klerman G. Secondary mania. Manic syndromes associated with antecedent physical illness or drugs. Arch Gen Psychiatry. 1978; 35: 1333-1339.

26. Strakowski SM, MeElroy SL, Keck PW Jr, West SA. The co-occurrence of mania with medical and other psychiatric disorders. Int J Psychiatry Med. 1994; 24: 305-328.

27. Larson EW, Richelson E. Organic causes of mania. Mayo Clin Proc. 1988; 63: 906-912.

28. Brooks JO 3rd, Hoblyn JC. Secondary mania in older adults. Am J Psychiatry. 2005; 162: 20332038.

29. Van Gerpen MW, Johnson JE, Winstead DK. Mania in the geriatric patient population: A review of the literature. Am J Geriatr Psychiatry. 1999; 7: 188-202.

30. Cummings JL, Mendez MF. Secondary mania with focal cerebrovascular lesions. Am J Psychiatry. 1984; 141: 1084-1087.

31. Schmidt U, Miller D. Two cases of hypomania in AIDS. Br J Psychiatry. 1988; 152: 839-842.

32. Bostock EC, Kirkby KC, Garry MI, Taylor BV. Comparison of precipitating factors for mania and partial seizures: Indicative of shared pathophysiology? J Affect Disord. 2015; 183: 57-67.

33. Galasko D, Kwo-On-Yuen PF, Thal L. Intracranial mass lesions associated with late-onset psychosis and depression. Psychiatr Clin North Am. 1988; 11: 151-166.

34. Cipriani G, Picchi L, Vedovello M, Nuti A. Reversible dementia from corticosteroid therapy. Clin Geriatr. 2012; 20: 38-41.

35. Dubovsky SL. Mania. Continuum (Minneap Minn). 2015; 21 (3 Behavioral Neurology and Neuropsychiatry): 737-755.

36. Gross JJ. The emerging field of emotion regulation: An integrative review. Rev Gen Psychol. 1998; 2: 271-299.

37. Mendez MF. Mania in neurologic disorders. Curr Psychiatry Rep. 2000; 2: 440-445.

38. Shulman KI. Disinhibition syndromes, secondary mania and bipolar disorder in old age. J Affect Disord. 1997; 46: 175-182.

39. Starkstein SE, Boston JD, Robinson RG. Mechanisms of mania after brain injury. 12 case reports and review of the literature. J Nerv Ment Dis. 1988; 176: 87-100.

40. Lloyd GG. Acute behaviour disturbances. J Neurol Neurosurg Psychiatr. 1993; 56: 1149-1156. 
41. Robinson G. The clinical neuropsychiatry of stroke. Cognitive, behavioral and emotional disorders following vascular brain injury. 2nd ed. Second. Cambridge University Press; 2006. p. 306.

42. Robinson RG, Starkstein SE. Neuropsychiatric aspects of cerebrovascular disorders. In: Yudofsky SC, Hales RE editors. The American Psychiatric Press Textbook of Neuropsychiatry. Washington, DC: American Psychiatric Press; 1997. pp. 607-673.

43. Robinson RG, Boston JD, Starkstein SE, Price TR. Comparison of mania and depression after brain injury: Causal factors. Am J Psychiatry. 1988; 145: 172-178.

44. Gafoor R, O'Keane V. Three case reports of secondary mania: Evidence supporting a right frontotemporal locus. Eur Psychiatry. 2003; 18: 32-33.

45. Amino Y, Kyuhou S, Matsuzaki R, Gemba H. Cerebellothalamocortical projections to the posterior parietal cortex in the macaque monkey. Neurosci Lett. 2001; 309: 29-32.

46. Nagao S. Pontine nuclei-mediated cerebello-cerebral interaction and its functional role. Cerebellum. 2004; 3: 11-15.

47. Nishio $Y$, Ishii K, Kazui H, Hosakai Y, Mori E. Frontallobe syndrome and psychosis after damage to the brainstem dopaminergic nuclei. J Neurol Sci. 2007; 260: 271-274.

48. Davidson RJ. Anterior cerebral asymmetry and the nature of emotion. Brain Cogn. 1992; 20: 125-151.

49. Lyketsos CG, Corazzini K, Steele C. Mania in Alzheimer's disease. J Neuropsychiatry Clin Neurosci. 1995; 7: 350-352.

50. Depp CA, Jeste DV. Bipolar disorder in older adults. A critical review. Bipolar Disorders. 2006; 6: 343-367.

51. Taylor M, Abrams R. Manic states: A genetic study of early and late onset affective disorders. Arch Gen Psychiatry. 1973, 28: 656-658.

52. Kennedy N, Everitt B, Boydell J, Van Os J, Jones PB, Murray RM. Incidence and distribution of first-episode mania by age: Results from a 35-year study. Psychol Med. 2005; 35: 855-863.

53. Broadhead J, Jacoby R. Mania in old age: A first prospective study. J Geriatr Psychiatry. 1990; 5: 215-222.

54. George LK. Social and economic factors related to psychiatric disorders in late life. In E. W. Busse and D. G. Blazer editors. Textbook of Geriatric Psychiatry. Washington, DC: American Psychiatric Press; 1996. pp. 129-153.

55. Slater E, Roth M. In Clinical Psychiatry, 3rd edn revised. Mayer-Gross W, Slater E,. Roth M editors. London: Bailliere, Tindall, and Cassell; 1977. pp. 571-572, 600.

56. Azorin JM, Kaladjian A, Adida M, Fakra E. Late-onset bipolar illness: The geriatric bipolar type VI. CNS Neurosci Ther. 2012; 18: 208-213.

57. McDonald WM, Wermager J. Pharmacologic treatment of geriatric mania. Curr Psychiatry Rep. 2002; 4: 43-50.

58. Tohen M, Shulman KI, Satlin A. First-episode mania in late life. Am J Psychiatry. 1994; 151 : 130-132.

59. Burns A. Disorders of affect in Alzheimer's disease. Int J Geriatr Psychiatr. 1990; 5; 63-66.

60. Cipriani G, Danti S, Carlesi C, Cammisuli DM, Di Fiorino M. Bipolar disorder and cognitive dysfunction: A complex link. J Nerv Ment Dis. 2017; 205: 743-756. 
61. Nilsson FM, Kessing LV, Sørensen TM, Andersen PK, Bolwig TG. Enduring increased risk of developing depression and mania in patients with dementia. J Neurol Neurosurg Psychiatry. 2002; 73: 40-44.

62. Ng B, Camacho A, Lara DR, Brunstein MG, Pinto OC, Akiskal HS. A case series on the hypothesized connection between dementia and bipolar spectrum disorders: Bipolar type VI? J Affect Disord. 2008; 107: 307-315.

63. Spicer CC, Hare EH, Slater E. Neurotic and psychotic forms of depressive illness: Evidence from age-incidence in a national sample. Br J Psychiatry. 1973; 123: 535-541.

64. Stone K. Mania in the elderly. Br J Psychiatry. 1989; 155: 220-224.

65. Shulman K, Post F. Bipolar affective disorder in old age. Br J Psychiatry. 1980; 136: 26-32.

66. Shulman KI, Tohen M, Satlin A, Mallya G, Kalunian D. Mania compared with unipolar depression in old age. Am J Psychiatry. 199; 149: 341-345.

67. Appleby BS, Rosenberg P. Mania as a possible prodrome to dementia. J Neuropsychiatry Clin Neurosci. 2007; 19: 194.

68. Roiter B, Pigato G, Perugi G .Late-onset mania in a patient with movement disorder and basal ganglia calcifications: A challenge for diagnosis and treatment. Case Rep Psychiatry. 2016; 2016: 1393982.

69. Zahodne LB, Ornstein K, Cosentino S, Devanand DP, Stern Y. Longitudinal relationships between Alzheimer disease progression and psychosis, depressed mood, and agitation/aggression. Am J Geriatr Psychiatry. 2015; 23: 130-140.

70. Burns A, Jacoby R, Levy R. Psychiatric phenomena in Alzheimer's disease. III: Disorders of mood. Br J Psychiatry. 1990; 157: 81-86.

71. Hart DJ, Craig D, Compton SA, Critchlow S, Kerrigan BM, Mcllroy SP, et al. A retrospective study of the behavioural and psychological symptoms of mid and late phase Alzheimer's disease. Int J Geriatr Psychiatry. 2003; 18: 1037-1042.

72. Tseng WS, Tzeng NS. A rivastigmine-precipitated manic episode in a patient with Alzheimertype dementia. Int Psychogeriatr. 2012; 24: 1697-1669.

73. Hategan A, Bourgeois JA. Donepezil-associated manic episode with psychotic features: A case report and review of the literature. Gen Hosp Psychiatry. 2016; 38: 115.e1-115.e4.

74. Ehrt U, Fritze F, Aarsland D. Mania after administration of cholinesterase inhibitorsin patients with dementia and comorbid bipolar disorder: Two case reports. J Clin Psychopharmacol. 2011; 31: 254-256.

75. Cipriani G, Danti S, Carlesi C. Three men in a (same) boat: Alzheimer, Pick, Lewy. Historical notes. Eur Geriatr Med. 2016; 7: 526-530.

76. Cipriani G, Lucetti C, Danti S, Nuti A. Apathy and dementia. Nosology, assessment and management. J Nerv Ment Dis. 2014; 202: 718-724.

77. Cipriani G, Lucetti C, Vedovello $M$, Nuti A. Diogenes syndrome in patients suffering from dementia. Dialogues Clin Neurosci. 2012; 14: 455-460.

78. Cipriani G, Carlesi C, Lucetti C, Danti S, Nuti A. Eating behaviors and dietary changes in patients with dementia. Am J Alzheimers Dis Other Demen. 2016; 31: 706-716.

79. Cipriani G, Vedovello M, Ulivi M, Nuti A, Lucetti C. Repetitive and stereotypic phenomena and dementia. Am J Alzheimers Dis Other Demen. 2013; 28: 223-227.

80. Caycedo AM, Miller B, Kramer J, Rascovsky K. Early features in frontotemporal dementia. Curr Alzheimer Res. 2009; 6: 337-340. 
81. Woolley JD, Wilson MR, Hung E, Gorno-Tempini ML, Miller BL, Shim J. Frontotemporal dementia and mania. Am J Psychiatry. 2007; 164: 1811-1816.

82. Neary D, Snowden JS, Mann DM. Classification and description of frontotemporal dementias. Ann N Y Acad Sci. 2000; 920: 46-51.

83. Mendez MF, Carr AR, Paholpak P. Psychotic-like speech in fron-totemporal dementia. J Neuropsychiatry Clin Neurosci. 2017; 29: 183-185.

84. Mendez MF, Chen AK, Shapira JS, Lu PH, Miller BL. Acquired extro-version associated with bitemporal variant of frontotemporal dementia. J Neuropsychiatry Clin Neurosci. 2006; 18: 100-107.

85. Mendez MF, McMurtray A, Chen AK, Shapira JS, Mishkin F, Miller BL. Functional neuroimaging and presenting psychiatric features in frontotemporal dementia. J Neurol Neurosurg Psychiatry. 2006; 77: 4-7.

86. Mendez M. Manic behavior and asymmetric right frontotemporal dementia from a novel progranulin mutation. Neuropsychiatr Dis Treat. 2018; 14: 657-662.

87. Dols A, Krudop W, Möller C, Shulman K, Sajatovic M, Pijnenburg YA. Late life bipolar disorder evolving into frontotemporal dementia mimic. Neuropsychiatr Dis Treat. 2016; 12: 2207-2212.

88. Meisler MH, Grant AE, Jones JM, Lenk GM, He F, Todd PK, et al. C9ORF72 expansion in a family with bipolar disorder. Bipolar Disord. 2013; 1: 326-332.

89. Cassidy F, Carroll BJ. Vascular risk factors in late onset mania. Psychol Med. 2002; 32: 359-362.

90. Steffans DC, Krishnan KRR. Structural neuroimaging and mood disorders. Recent findings, implications for classification, and future directions. Biol Psychiat. 1998; 43: 705-712.

91. Duggal HS, Singh I. New-onset vascular mania in a patient with chronic depression. J Neuropsychiatry Clin Neurosci. 2009; 21: 480-482.

92. Alexopoulous GS, Meyers BS, Young RC, Kakuma T, Silbersweig D, Charlson M. Clinically defined vascular depression. Am J Psychiat. 1997; 154: 562-565.

93. Santos CO, Caeiro L, Ferro JM, Figueira ML. Mania and Stroke: A Systematic Review. Cerebrovasc Dis. 2011; 32: 11-21.

94. Mimura M, Nakagome K, Hirashima N, Ishiwata H, Kamijima K, Shinozuka A. et al. Left frontotemporal hyperperfusion in a patient with post-stroke mania. Psychiatry Res. 2005; 139: 263-267.

95. Kumar S, Jacobson RR, Sathananthan K. Sathananthan, Seasonal cyclothymia to seasonal bipolar affective disorder: A double switch after stroke. J Neurol Neurosurg Psychiatry. 1997; 6: 796-797.

96. Starkstein SE, Robinson RG. Affective disorders and cerebral vascular disease. Br J Psychiatry. 1989; 154: 170-182.

97. Liu CY, Wang SJ, Fuh JL, Yang YY, Liu HC. Bipolar disorder following a stroke involving the left hemisphere. Aust NZ J Psychiatry. 1996; 30: 688-691.

98. Takahashi K, Oshima A, Ida I, Kumano H, Yuuki N, Fukuda M, et al. Relationship between age at onset and magnetic resonance image-defined hyperintensities in mood disorders. J Psychiatr Res. 2008; 42: 443-450.

99. Shulman KI, Herrmann N. The nature and management of mania in old age. Psychiatr Clin North Am. 1999; 22: 649-665.

100.Fujikawa T, Yamawaki S, Touhouda Y. Silent cerebral infarctions in patients with late-onset mania. Stroke. 1995; 26: 946-949. 
101.Santos CO, Caeiro L, Ferro JM, Figueira ML. Mania and stroke: A systematic review. Cerebrovasc Dis. 2011; 32: 11-21.

102. Routh R, Hill A. Post-stroke mania: A rare but treatable presentation. Progr Neurol Psychiatr. 2014; 18: 24-25.

103. Watanabe $\mathrm{Y}$, Shioiri $\mathrm{T}$, Kuwabara $\mathrm{H}$, Someya $\mathrm{T}$. Mania after vascular dementia in a patient with bipolar II disorder. Psychiatry Clin Neurosci. 2006; 6: 117-118.

104. Hain C, Peter K. Erstmanifestation eines manischen Syndroms im hoheren Lebensalter bei subkortikaler arteriosklerotischer Enzephalopathie (Morbus Binswanger). Psychiatr Prax. 1999; 26: 305-307.

105.Bangash A, Saad K. Bipolar disorder against a background of a rare vascular dementia. Progr Neurol Psychiatr. 2016; 20: 10-12.

106. Mullan E, Cooney C, Jones E. Mania and cortical Lewy Body Dementia. Int J Geriatr Psychiatry. 1996; 11: 837-839.

107.Prado E, Paholpak P, Ngo M, Porter V, Apostolova LG, Marrocos R, et al. Agitation and psychosis associated with dementia with lewy bodies exacerbated by modafinil use. Am J Alzheimers Dis Other Demen. 2012; 27: 468-473.

108.Parkinson J. An essay on the shaking palsy. London: Sherwood, Neely, and Jones; 1817.

109.Aarsland D, Bronnick K, Alves G, Tysnes OB, Pedersen KF, Ehrt U, et al. The spectrum of neuropsychiatric symptoms in patients with early untreated Parkinson's disease. J Neurol Neurosurg Psychiatry. 2009; 80: 928-930.

110.McKeith I, Dickson DW, Lowe J, Emre M, O'Brien JT, Feldman H, et al. Dementia with Lewy bodies: Diagnosis and management: Third report of the DLB Consortium. Neurology. 2005; 65: 1863-1872.

111.Mindham RHS. Psychiatric symptoms in parkinsonism. Neurol Neurosurg Psychiatry. 1970; 33: 188-191.

112.Shulman KT, Satlin JM. Mania compared with unipolar depression in old age. Ame J Psychiat. 1992; 149: 341-345.

113.Goodwin FK. Psychiatric side-effects of levodopa in man. JAMA. 1971; 218: 1915-1920.

114. Menza MA, Colbe L. Hypomania in a patient receiving deprenyl (selegiline) after adrenalstriatal transplantation of Parkinson's disease. Clin Neuropharmacol. 1988; 11: 549-550.

115.Jouvent R, Abensour P, Bonnet AM, Widlocher D, Agid Y, Lhermitte F. Antiparkinsonian and antidepressant effects of high doses of bromocriptine. J Affect Disord. 1983; 5: 141 -145.

116.Singh A, Althoff R, Martineau RJ, Jacobson J. Pramipexole, ropinirole, and mania in Parkinson's disease. Am J Psychiatry. 2005; 162: 814-815.

117.Przedborski S, Liard A, Hildebrand J. Induction of mania by apomorphine in a depressed Parkinsonian patient. Mov Disord. 1992; 7: 285-286.

118.Kim E, Zwil AS, McAllister TW, Glosser DS, Stern M, Hurtig H. Treatment of organic bipolar mood disorders in Parkinson's disease. J Neuropsychiatry Clin Neurosci. 1994; 6: 181-184.

119. Thomas N, Jebaraj P, Kishor Kumar S. Bipolar affective disorder in Parkinson's disease: Clinical dilemmas. Indian J Med Sci. 2008; 62: 374-376.

120.Giovannoni G, O'Sullivan JD, Turner K, Manson AJ, Lees AJ. Hedonistic homeostatic dysregulation in patients with Parkinson's disease on dopamine replacement therapies. J Neurol Neurosurg Psychiatry. 2000; 68: 423-428. 
121.Limotai N, Oyama G, Go C, Bernal O, Ong T, Moum SJ, et al. Addiction-like manifestations and Parkinson's disease: A large single center 9-year experience. Int J Neurosci. 2012; 122: 145153.

122.Kummer A, Dias FM, Cardoso F, Teixeira AL. Low frequency of bipolar disorder, dopamine dysregulation syndrome, and punding in Brazilian patients with Parkinson's disease. Braz J Psychiatry. 2010; 32: 62-65.

123.Mendez MF. Huntington's disease: Update and review of neuropsychiatrie aspects. Int J Psychiatry Med. 1994; 24: 189-208.

124.Rosenblatt A. Neuropsychiatry of Huntington's disease. Dialogues Clin Neurosci. 2007; 9: 191197.

125. Folstein SE, Chase G, Wahl W, McDonnel AM, Folstein MF. Huntington's disease in Maryland: Clinical aspects of racial variation. Am J Hum Genet. 1987; 41: 168-179.

126. Rosenblatt A, Leroi I. Neuropsychiatry of Huntington's disease and other basal ganglia disorders. Degenerative diseases of the basal ganglia, such as Huntington's disease (HD), Parkinson's disease, and Wilson's disease, postencephalitic parkinsonism and Fahr's disease. Psychosomatics. 2000; 41: 24-30.

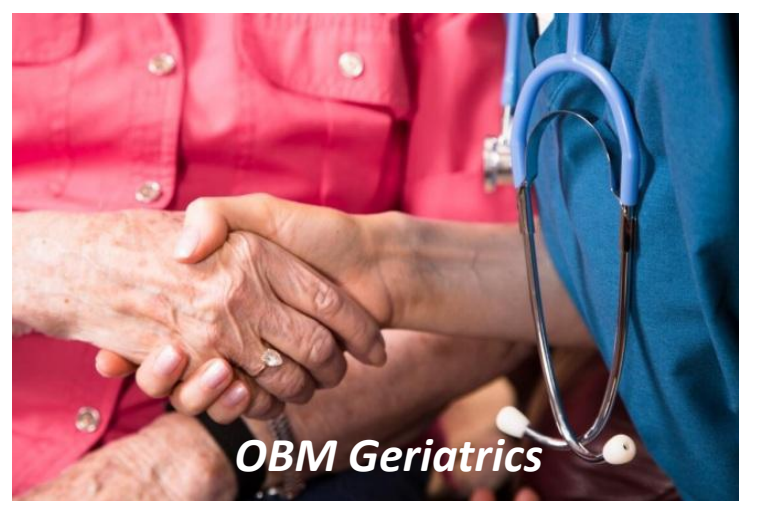

Enjoy OBM Geriatrics by:

1. Submitting a manuscript

2. Joining in volunteer reviewer bank

3. Joining Editorial Board

4. Guest editing a special issue

For more details, please visit: http://www.lidsen.com/journals/geriatrics 